\title{
TP53 codon 72 polymorphism in radiation-associated human papillary thyroid cancer
}

\author{
TATIANA I. ROGOUNOVITCH ${ }^{1}$, VLADIMIR A. SAENKO ${ }^{1,2}$, KIYOTO ASHIZAWA ${ }^{3}$, ILYA A. SEDLIAROU ${ }^{1}$, \\ HIROYUKI NAMBA ${ }^{1}$, ALEKSANDR Yu. ABROSIMOV ${ }^{1,2}$, EUGENY F. LUSHNIKOV ${ }^{2}$, \\ PAVEL O. ROUMIANTSEV ${ }^{2}$, MARINA V. KONOVA ${ }^{2}$, NATALIA S. PETOUKHOVA ${ }^{2}$, \\ IRINA V. TCHEBOTAREVA ${ }^{2}$, VIKTOR K. IVANOV ${ }^{2}$, SERGEI Yu. CHEKIN ${ }^{2}$, TATIANA I. BOGDANOVA ${ }^{4}$, \\ MYKOLA D. TRONKO ${ }^{4}$, ANATOLY F. TSYB ${ }^{2}$, GERRY A. THOMAS ${ }^{5}$ and SHUNICHI YAMASHITA ${ }^{1,6}$ \\ ${ }^{1}$ Nagasaki University Graduate School of Biomedical Sciences, 1-12-4 Sakamoto, Nagasaki 852-8523, Japan; \\ ${ }^{2}$ Medical Radiological Research Center of Russian Academy of Medical Sciences, 4 Korolev Str., Obninsk 249034, \\ Russian Federation; ${ }^{3}$ Radiation Effect Research Foundation, 1-8-6 Nakagawa, Nagasaki 850-0013, Japan; ${ }^{4}$ Institute \\ of Endocrinology and Metabolism of Academy of Medical Sciences of Ukraine, 69 Vishgorodskaya Str., Kiev 254114, \\ Ukraine; ${ }^{5}$ South West Wales Cancer Institute, Singleton Hospital, Sketty Lane, Swansea SA2 8QA, UK; \\ ${ }^{6}$ World Health Organization/HQ, 20 Avenue Appia CH-1211, Geneva 27, Switzerland
}

Received October 24, 2005; Accepted December 22, 2005

\begin{abstract}
The study investigated an association between the germline polymorphism at TP53 codon 72 and the development of papillary thyroid cancer (PTC) following exposure to radiation from the Chernobyl accident. TP53 genotype was examined in 48 pediatric/adolescent (age at diagnosis $<18$ years) and 68 adult post-Chernobyl patient with PTC, 53 adult patients with sporadic PTC and 313 healthy individuals from Russian-Ukrainian population. In addition, we evaluated loss of heterozygosity for TP53 and the allele expression ratio. The genotype of the patients was correlated with clinicopathological data. Arg TP53 homozygotes were found to be significantly underrepresented among adults with postChernobyl PTC, but not in children and adolescents when compared with sporadic PTC cases and the general population. In the tumors, cell transformation did not lead to allelic loss or biased TP53 allele expression in heterozygous individuals. None of TP53 genotypes specifically associated with tumor stage and morphology, however there were particular correlations with lymph node status in certain age groups of radiation-associated cases not seen in sporadic PTCs. The findings suggest TP53 allele combinations other than Arg/Arg
\end{abstract}

Correspondence to: Dr Vladimir Saenko, Department of International Health and Radiation Research, Atomic Bomb Disease Institute, Nagasaki University Graduate School of Biomedical Sciences, 1-12-4 Sakamoto, Nagasaki 852-8523, Japan

E-mail: saenko@net.nagasaki-u.ac.jp

Key words: papillary thyroid cancer, radiation, TP53 polymorphism, Chernobyl, cancer risk may contribute to the risk of development of PTC in individuals exposed to radiation during their late childhood, adolescence or in young adulthood.

\section{Introduction}

p53 protein plays a key role in a variety of cellular processes mediating cell cycle arrest, apoptosis, senescence and DNA repair. Somatic mutation of TP53 is known to be one of the most frequent genetic alterations in cancer being detected in about $50 \%$ of human malignancies (1). The mutation may result in compromised protein function and potentially contribute to tumor growth and genomic instability.

p53 levels in a cell may change dramatically following exposure to stress e.g. ionizing or UV radiation, hypoxia, heat shock, growth factor withdrawal, oncogene activation and exposure to cytotoxic drugs $(2,3)$. Elevation of p53 intracellular content is largely attributed to increased protein stability which is achieved by multiple posttranslational modifications resulting in its attenuated proteosomal degradation.

p53-regulated apoptosis in insulted cells is exerted both by transcription-dependent and transcription-independent mechanisms. With regard to the latter, after hypoxia and DNA damage, p53 has been shown to be able to translocate to mitochondria where it can interact with and impair antiapoptotic Bcl-2 and BCL- $\mathrm{X}_{\mathrm{L}}$ proteins $(4,5)$. At least in part, p53 translocation to mitochondria is dependent on the p53 variant structure. It has been demonstrated that p53 with an arginine residue at amino acid position 72 (72Arg) reaches the organelle and induces apoptosis through cytochrome $c$ release more efficiently than the p53 72Pro variant (6). The two p53 isoforms with either 72Arg or 72Pro are the result of a common polymorphism in exon 4 of TP53 gene (encoded by CGC and CCC codons, respectively). This single nucleotide polymorphism occurs in the fragment of the gene encoding a 
proline-rich region (residues 61-94) of the protein which is essential for apoptosis and growth suppression, but not for transactivation of the p53 target genes (7).

The p53 72Arg/Pro polymorphism has been, sometimes controversially, associated with various human malignancies, such as breast $(8,9)$, cervical $(10,11)$ and lung cancer $(12)$, cutaneous squamous cell carcinoma in renal transplant patients (13) and sporadic thyroid cancer $(14,15)$. No significant relationship between 72Arg/Pro p53 polymorphism has been found in hepatocellular (16), ovarian (17), brain (18), cervical (19-21), colorectal (9) and other digestive tract cancers (22). Thus, it is likely that in several types of human malignancies not only mutated p53, but also functional p53 variants may affect the tumor development.

Thyroid gland is well known to be an organ particularly vulnerable to radiation (23). After the Chernobyl accident in 1986, incidence of papillary thyroid cancer (PTC) sharply increased especially in the individuals exposed at the young age $(24,25)$. It is believed that TP53 mutation does not associate with well-differentiated thyroid cancer (such as PTC) and therefore cannot serve as a pathognomonic marker of radiationinduced disease. Indeed, TP53 mutations in both radiationinduced and sporadic PTCs were shown to be infrequent. Only 1-3\% of radiation-induced (26-28) and comparable proportion of spontaneous PTCs have been reported to harbor TP53 alterations (29). On the other hand, normal thyrocytes, similarly to many other types of cells, show a dose-dependent increase and time-dependent changes of p53 level after radiation exposure accompanied by DNA repair in vitro (30).

Given that p53 is involved in radiation response of human thyrocytes and there is a difference in biological behavior between p53 polymorphic variants, we set out the study to determine TP53 allelic form prevalence in radiation-associated post-Chernobyl PTCs and to compare it to that in sporadic thyroid cancer and an ethnically matched general population to address a hitherto unanswered question whether p53 amino acid 72 polymorphism may be relevant to the risk of development of radiation-induced PTC.

\section{Materials and methods}

Patients and control subjects. The study included DNA samples from 169 PTC patients from Ukraine and Russia and 313 ethnically matched healthy individuals. Among the thyroid cancer cases, we distinguished two different etiopahtogenic types, the radiation-associated PTCs (thyroid cancer in residents of the territories of Ukraine and Russia contaminated with radioisotopes after the Chernobyl accident, $\mathrm{n}=116$ ) and sporadic PTCs (no history of radiation exposure, $n=53$ ). The radiationassociated PTCs included 97 post-Chernobyl cases from patients whose age at the moment of exposure to radioiodine from the Chernobyl accident (April, 1986) was 0-18 years old and additionally 19 PTC cases from adult female patients whose age at the time of the Chernobyl accident was 18-30 years. Radiation risks for thyroid cancer have been recently validated in the latter subgroup of the population exposed to radionuclides after the Chernobyl fallout (31) therefore such cases were combined in this study with those traditionally assigned radiation-induced post-Chernobyl PTCs (aged at exposure 0-18 years). In the radiation-associated group, there were 48 pediatric/adolescent cases (patients aged $<18$ years at diagnosis) and 68 adult PTCs. All patients from both radiation-associated and sporadic PTC groups were operated on for thyroid cancer in 1996-2003. The control group was composed of Caucasian volunteers, residents of Russia, who agreed to anonymously donate a buccal specimen with only gender and age at sampling recorded. Initially approached 454 individuals, donated 321 specimens $(70.7 \%$, response rate; in 8 cases DNA extraction failed). Demographic and clinicopathological characteristics of the subjects included in the study are listed in Table I.

Specimens. Snap-frozen thyroid tumor and matched normal tissue specimens were collected from the patients in Medical Radiological Research Center of Russian Academy of Medical Sciences (MRRC RAMS, Obninsk, Russia) with appropriate informed consent (30 of 97 post-Chernobyl PTCs and 19 PTCs in female patients described above in the radiation-associated group, and all sporadic PTCs).

DNA samples from post-Chernobyl Ukrainian radiationassociated PTCs (67 cases, ready to use DNA from the tumor and normal thyroid tissue) were provided by the Chernobyl Tissue Bank (URL, http://www .chernobyltissuebank.com/).

DNA was purified from frozen thyroid tissues and buccal swabs using a standard proteinase $\mathrm{K} /$ phenol-chloroform protocol and BuccalAmp DNA Extraction Kit (Epicentre, Madison, WI, USA), respectively. The study was approved by the respective ethics boards of Nagasaki University and MRRC RAMS.

Arg72Pro polymorphism by real-time PCR allelic discrimination assay. To detect the polymorphism, we designed two primers, TP53Ex4F (5'-CGTCCCAAGCAATGGATGA TT-3', pos. 532-552 in the sequence available under GenBank accession number AF136270) and TP53Ex4R (5'-CCGGTGT AGGAGCTGCTGG-3', pos. 654-672), and two sense strand TaqMan probes (synthesized at Applied Biosystems Japan facility), TP53Arg (5'-FAM-CTCCCCGCGTGGCCCCTAMRA-3', pos. 634-649) and TP53Pro (5'-VIC-CTCCCCㅌ CGTGGCCCC-TAMRA-3') specific to the alleles encoding for $72 \mathrm{Arg}$ and $72 \mathrm{Pro}$, respectively. The $25 \mu \mathrm{l}$ reaction mixture contained 10-50 ng of DNA as a template, $12.5 \mu 1$ of the TaqMan 2X PCR master mix (Applied Biosystems, Roche, Branchburg, NJ, USA), $800 \mathrm{nM}$ of each primer and $400 \mathrm{nM}$ of each probe. The reactions were performed in duplicates in an ABI PRISM 7700 Sequence Detector (Applied Biosystems, USA). PCR conditions were as follows: $50^{\circ} \mathrm{C}$ for $2 \mathrm{~min}, 95^{\circ} \mathrm{C}$ for $10 \mathrm{~min}$, then 35 cycles of $95^{\circ} \mathrm{C}$ for $15 \mathrm{sec}$ and $61^{\circ} \mathrm{C}$ for $1 \mathrm{~min}$.

Direct sequencing. For PCR amplification and direct sequencing of the fragment of TP53 exon 4, two primers were used: forward 5'-TCCCCCTTGCCGTCCCAA-3' (pos. 522-539) and reverse 5'-CGTGCAAGTCACAGACTT-3' (pos. 783-800). The reaction was performed in a $25 \mu 1$ mixture containing 50-100 ng of DNA template, $200 \mathrm{nM}$ of each primer, $2.5 \mu \mathrm{l}$ of 10X PCR Gold Buffer, $0.8 \mathrm{mM}$ of dNTPs, $1.5 \mathrm{mM}$ of $\mathrm{MgCl}_{2}$ and 1.25 units of AmpliTaq Gold DNA Polymerase (all reagents from Applied Biosystems, USA). PCR conditions were as follows: $95^{\circ} \mathrm{C}$ for $10 \mathrm{~min}$, then 35 cycles of 
Table I. Summary of PTC patients and controls included in the study.

\begin{tabular}{|c|c|c|c|c|c|}
\hline & \multicolumn{3}{|c|}{ Radiation-associated PTC, $(n=116)$} & \multirow{2}{*}{$\begin{array}{c}\text { Sporadic } \\
\text { PTC } \\
(n=53)\end{array}$} & \multirow{2}{*}{$\begin{array}{c}\text { Control } \\
\text { Population } \\
(n=313)\end{array}$} \\
\hline & $\begin{array}{l}\text { Pediatric/adolescent } \\
\qquad(\mathrm{n}=48)\end{array}$ & $\begin{array}{l}\text { Adult } \\
(\mathrm{n}=68)\end{array}$ & $\begin{array}{c}\text { Total } \\
(\mathrm{n}=116)\end{array}$ & & \\
\hline Gender, F/M (ratio) & $31 / 17(1.8: 1)$ & $55 / 13(4.2: 1)$ & $86 / 30(2.9: 1)$ & $45 / 8(5.6: 1)$ & $171 / 142(1.2: 1)$ \\
\hline $\begin{array}{l}\text { Age at diagnosis, years, } \\
\text { range (median) }\end{array}$ & $\begin{array}{l}>0-18 \\
(15)\end{array}$ & $\begin{aligned} \geq & 18-44 \\
& (25)\end{aligned}$ & $\begin{array}{c}>0-44 \\
(21)\end{array}$ & $\begin{array}{c}26-76 \\
(48)\end{array}$ & $\begin{array}{c}16-68^{a} \\
(37)\end{array}$ \\
\hline $\begin{array}{l}\text { Age at exposure, years, } \\
\text { range (median) }\end{array}$ & $\begin{array}{c}>0-6.4 \\
(1.2)\end{array}$ & $\begin{array}{l}4.5-30 \\
(24)\end{array}$ & $\begin{array}{c}>0-30 \\
(8)\end{array}$ & $\mathrm{NA}^{\mathrm{b}}$ & NA \\
\hline $\begin{array}{l}\text { Period of latency, years, } \\
\text { range (median) }\end{array}$ & $\begin{array}{l}10.6-15.5 \\
\quad(13)\end{array}$ & $\begin{array}{l}11.2-17.5 \\
(14)\end{array}$ & $\begin{array}{c}10.0-17.5 \\
(14)\end{array}$ & NA & NA \\
\hline \multicolumn{6}{|l|}{ Tumor morphology $y^{c}$} \\
\hline Solid & 14 & 5 & 19 & 1 & NA \\
\hline Follicular & 14 & 29 & 43 & 7 & NA \\
\hline Papillary & 19 & 34 & 53 & 43 & NA \\
\hline \multicolumn{6}{|l|}{ Clinical class $^{\mathrm{d}}$} \\
\hline I & 17 & 31 & 48 & 26 & NA \\
\hline II & 15 & 18 & 33 & 12 & NA \\
\hline III & 12 & 14 & 26 & 14 & NA \\
\hline IV & 4 & 5 & 9 & 1 & NA \\
\hline \multicolumn{6}{|l|}{ Nodal status } \\
\hline Negative & 19 & 34 & 53 & 34 & NA \\
\hline Positive & 29 & 34 & 63 & 19 & NA \\
\hline \multicolumn{6}{|l|}{ Distant metastases } \\
\hline Negative & 44 & 63 & 107 & 52 & NA \\
\hline Positive & 4 & 5 & 9 & 1 & NA \\
\hline
\end{tabular}

${ }^{a}$ Age was recorded at the moment of sampling. ${ }^{b} \mathrm{NA}$, not applicable. ${ }^{\mathrm{c}}$ Morphology is stratified for major histological component of the tumor; data were available for 47 pediatric/adolescent and 68 adult radiation-associated PTCs, and 51 sporadic PTCs. ${ }^{\mathrm{d}}$ Tumor staging was performed according to De Groot et al (33).

$95^{\circ} \mathrm{C}$ for $30 \mathrm{sec}, 54^{\circ} \mathrm{C}$ for $30 \mathrm{sec}, 72^{\circ} \mathrm{C}$ for $30 \mathrm{sec}$ and finally $10 \mathrm{~min}$ at $72^{\circ} \mathrm{C}$. After visualization in a $1.5 \%$ TAE agarose gel, remaining PCR products $(5 \mu \mathrm{l})$ were treated with ExoSAP-IT PCR clean-up reagent (USB Corp., USA) and sequenced in both directions on an ABI 3100 automated sequencer (Applied Biosystems, USA) using Big Dye Terminator v3.1 Cycle Sequencing reagents (Applied Biosystems, Warrington, UK) and either forward or reverse primer.

Expression levels of TP53 allelic variants. RNA was extracted from frozen tumor and normal thyroid tissues with Isogen reagent (Nippon Gene, Tokyo, Japan) according to the manufacturer's protocol. To avoid DNA contamination, $10 \mu \mathrm{g}$ of total RNA was treated with 2.5 units of RNAse-free DNAse I (Takara, Tokyo, Japan) for $30 \mathrm{~min}$ at $37^{\circ} \mathrm{C}$, heated at $70^{\circ} \mathrm{C}$ for $30 \mathrm{~min}$ and recovered with Isogen. First strand cDNA was synthesized from $2 \mu \mathrm{g}$ of DNAse I-treated RNA in the presence of random hexamers and MuLV reverse trans- criptase (Applied Biosystems, Foster City, CA, USA). Efficacy of DNAse I treatment was assured by the absence of a $113 \mathrm{bp}$ PCR product after an extensive amplification (40 cycles) of a portion of human $T G$ gene (encodes thyroglobulin) using forward primer located in intron 10 of the gene (5'-GTGAG GGCACACATGCTTCAT-3', pos. 61-81 in the sequence available under GenBank accession number X06070) and reverse primer located in $T G$ exon 11 (5'-CGGAGCTTTGC TTCCTCACA-3', pos. 154-173) (data not shown). Thereafter, the relative expression of TP53 allelic forms was evaluated in heterozygous specimens by real-time PCR allelic discrimination assay as described above. For calibration, DNA templates with varying proportion $(0-100 \%)$ of either variant allele made by combining the corresponding homozygous DNA samples were used.

Tumor morphology and clinicopathological data. All tumors were diagnosed as PTCs according to the World Health 
A

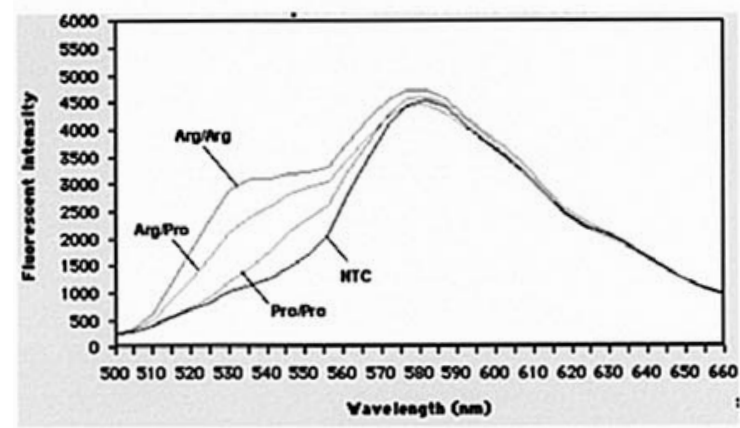

B

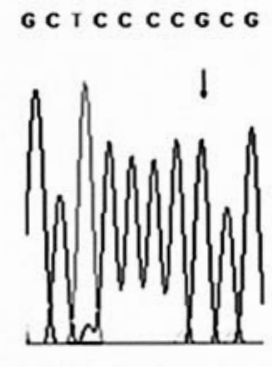

Arg/Arg

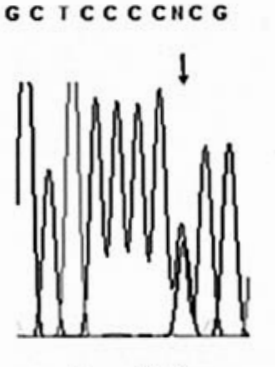

Arg/Pro

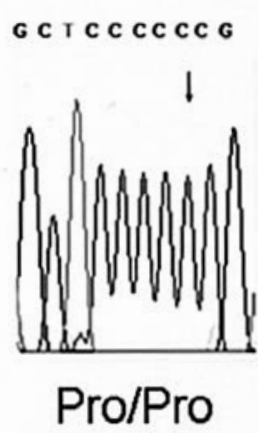

Figure 1. Detection of TP53 codon 72 polymorphism. (A), Real-time allelic discrimination assay. Three genotypes, homozygous Arg/Arg and Pro/Pro, and heterozygous Arg/Pro are clearly distinguishable yielding different fluorescence spectrum (annotated respectively in the image; NTC, non-template control). Picture was obtained using the Sequence Detection Software (Applied Biosystems, USA). (B), Direct sequencing of a fragment of TP53 exon 4 around the polymorphic site.

Organization histological typing of thyroid tumors classification (32). Morphological characteristics were provided by experienced pathologists (A.Yu.A., E.F.L. and T.I.B.) with respect to the tumor histological variant. Approximately a half of the tumors included in the study had mixed architecture, therefore the major component, i.e. papillary, follicular or solid, was considered for further analysis for simplicity. Information on tumor extent and metastatic lesions was retrieved from medical records. Tumor staging (clinical class) was performed as described (33).

Statistical analysis. Results were analyzed using SAS/STAT software package, SAS Institute Inc., USA (34). Statistical significance level was set to $\mathrm{P}<0.05$.

\section{Results}

Distribution of 72Arg/Pro polymorphic variants. TP53 codon 72 polymorphisms in different PTC groups and controls were examined by two independent methods, real-time PCR allelic discrimination assay and direct sequencing (Fig. 1). The two methods were always concordant. None of the groups deviated from Hardy-Weinberger equilibrium with the allele frequencies of 0.72 and 0.28 ( $A r g$ and Pro, respectively) in the population or significantly differed from each other by $\chi^{2}$ test. At the same time, analysis demonstrated that there was a significantly lower number of homozygous Arg cases in the adult radiationassociated group as compared to general population and sporadic PTCs whereas none of the other groups displayed such a feature (Table II). In the younger patients with radiationrelated PTC, the frequency of the homozygous Arg genotype was somewhat lower than in sporadic PTCs and in controls but this difference was insignificant. Neither sporadic PTC group vs. controls nor the two radiation-associated PTC groups displayed a significant difference for either genotype upon comparison.

The prevalence of heterozygous Arg/Pro genotype was elevated in the adult radiation-associated PTC group. Statistical analysis detected a significant difference between Arg/Pro rate in this group compared to sporadic PTCs. Comparison to population control also detected the increased prevalence of Arg/Pro cases in the adult radiation-associated group but threshold of significance was not reached. None of the other groups was found to be significantly different for this genotype in any combination.

Homozygous Pro genotype was relatively rare in any of the groups examined and resulted in insignificant difference between the radiation-associated cases and other groups. Also, no statistical difference was found between sporadic PTCs and controls.

Taken together, results demonstrate that the radiationassociated PTC group is characterized by an underrepresentation of the homozygous 72Arg-encoding genotype due to its significantly lowered prevalence in adult cases. This decrease may be largely attributed to the shift from homozygous Arg/Arg to heterozygous Arg/Pro genotype in this group.

In addition, we analyzed allele frequency association with individuals' gender and age. No correlation with gender $(\mathrm{P}=0.73)$ or age dependence $(\mathrm{P}=0.41$ for trend) was detected using population control as a group for calculations.

Loss of heterozygosity of TP53 in PTCs. To detect possible allelic loss in the tumor, DNA specimens from corresponding normal thyroid tissue of the cases determined to be homozygous for either of genotypes in the tumor were subjected to allelic discrimination assay. Comparison of the TP53 status in the tumor and normal thyroid tissue showed perfect match between the two types of DNA from the same individual (data not shown) consistent with known infrequent alterations of the TP53 locus in differentiated thyroid cancers.

Expression levels of TP53 72Arg and 72Pro-encoding alleles in tumor and normal thyroid tissues. The proportion of individuals heterozygous for the TP53 Arg/Pro polymorphism was relatively high in both radiation-associated and sporadic PTC groups. To evaluate the expression levels of each of the TP53 alleles in the tumor and normal thyroid tissue in such individuals, DNA-free RNA was purified, reverse transcribed and analyzed by real-time PCR. Relative expression 
Table II. Prevalence of TP53 genotypes in various PTC groups and controls.

\begin{tabular}{|c|c|c|c|}
\hline Group & $\operatorname{Arg} / \operatorname{Arg}(\mathrm{OR} ; 95 \% \mathrm{CI})^{\mathrm{a}}$ & Arg/Pro (OR; 95\% CI) & Pro/Pro (OR; 95\% CI) \\
\hline \multicolumn{4}{|c|}{ Population controls vs. other groups } \\
\hline Referent group, $(n=313)$ & $159(1.00)$ & $130(1.00)$ & $24(1.00)$ \\
\hline Rad PTCs <18 y.o., (n=48) & $23(0.89 ; 0.48-1.64)$ & $20(1.01 ; 0.54-1.86)$ & $5(1.40 ; 0.51-3.87)$ \\
\hline Rad adult PTCs ${ }^{c},(n=68)$ & $23\left(\mathbf{0 . 5 0} ; \mathbf{0 . 2 9 - 0 . 8 6 ) ^ { \mathrm { d } }}\right.$ & $37(1.68 ; 0.99-2.85)$ & $8(1.60 ; 0.69-3.75)$ \\
\hline Sporadic PTCs, $(\mathrm{n}=53)$ & $31(1.36 ; 0.76-2.46)$ & $18(0.72 ; 0.39-1.33)$ & $4(0.98 ; 0.33-2.96)$ \\
\hline \multicolumn{4}{|l|}{$\begin{array}{l}\text { Sporadic PTCs vs. radiation- } \\
\text { associated PTCs }\end{array}$} \\
\hline Referent group, $(\mathrm{n}=53)$ & $31(1.00)$ & $18(1.00)$ & $4(1.00)$ \\
\hline Rad PTCs <18 y.o., $(\mathrm{n}=48)$ & $23(0.65 ; 0.30-1.43)$ & $20(1.39 ; 0.62-3.12)$ & $5(1.42 ; 0.36-5.65)$ \\
\hline Rad adult PTCs, $(n=68)$ & $23(0.36 ; 0.17-0.76)$ & $37(2.32 ; 1.11-4.88)$ & $8(1.63 ; 0.46-5.75)$ \\
\hline Combined Rad PTCs, $(n=116)$ & $46(0.47 ; 0.24-0.90)$ & $57(1.88 ; 0.96-3.69)$ & $13(1.55 ; 0.48-4.99)$ \\
\hline \multicolumn{4}{|l|}{$\begin{array}{l}\text { Pediatric/adolescent PTCs vs. adult } \\
\text { radiation-associated PTCs }\end{array}$} \\
\hline Referent group, $(n=68)$ & $23(1.00)$ & $20(1.00)$ & $5(1.00)$ \\
\hline Rad adult PTCs, $(n=48)$ & $23(0.56 ; 0.26-1.18)$ & $37(1.67 ; 0.79-3.52)$ & $8(1.15 ; 0.35-3.75)$ \\
\hline
\end{tabular}

${ }^{a} \mathrm{OR}$, odds ratio; CI, confidence interval. ${ }^{\mathrm{b}}$ The abbreviation stands for pediatric/adolescent radiation-associated PTC group. ${ }^{\mathrm{c}}$ The abbreviation stands for adult radiation-associated PTC group. ${ }^{\mathrm{d} B o l d}$ typesetting denotes significance.

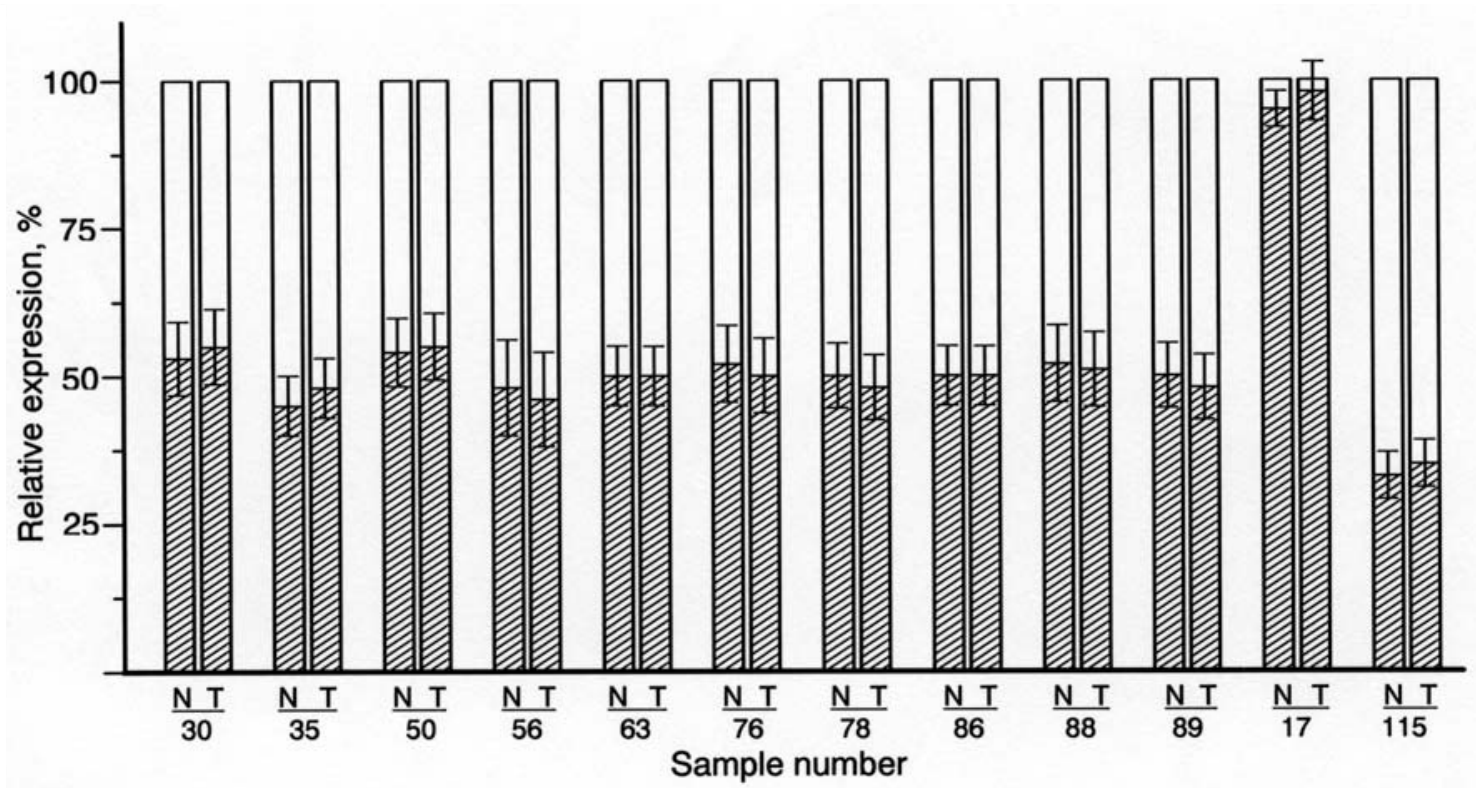

Figure 2. Relative expression levels of Arg and Pro TP53 alleles (open and hatched bars, respectively) in normal (N) and tumor (T) thyroid tissues in PTC patients heterozygous for codon 72. In most of cases, equivalent allele expression was detected (shown by cases 30 through 89). Imbalanced levels (demonstrated by cases 17 and 115 ) were found in less than $10 \%$ of patients.

levels of either allele were found to be balanced, being nearly equivalent in tumor tissue and normal counterpart in vast majority of cases (34 of 37 heterozygous cases examined, $91.9 \%$ ) in both radiation-associated and sporadic PTC groups (Fig. 2). Only 3 paired specimens, for unknown reasons, showed an imbalanced, Arg $>$ Pro or Arg $<$ Pro, profile which was present in both tumor and normal tissue (representatively shown in Fig. 2).

Correlation of TP53 polymorphism with tumor clinicopathological characteristics. Approximately a half of childhood/ adolescent PTCs $(23 / 47,48.9 \%)$ and a slightly smaller 
proportion of all adult cases (in total 50/119, 42.0\%) in our series showed mixed morphological architecture. When major histological component of a tumor (classic papillary, follicular or solid) was considered as a determinant, among the three PTC groups pediatric/adolescent cases differed from any other adult group significantly $(\mathrm{P}=0.016$ vs. radiationassociated adults, and $\mathrm{P}<0.0001$ vs. sporadic adults, $\chi^{2}$ test), and so did the two adult PTC groups $(\mathrm{P}=0.003)$ perhaps resulting from age difference among the corresponding individuals $(\mathrm{P}<0.0001$ by Mann-Whitney test for any group combination). Generally, there was a relatively increased proportion of tumors with solid and follicular components in younger patients and, vice versa, a higher prevalence of PTCs with classic papillary structure in adult groups. The radiation-associated adult group had intermediate characteristics between younger patients and sporadic adult cases. Analysis of genotype-morphology relationship within each separate PTC group performed for stratified major histological component of a tumor did not reveal significant statistical associations.

Assessment of TP53 variant correlation with other clinicopathological parameters showed no link to tumor stage and indices of tumor aggressiveness such as local lymph node involvement and presence of distant metastases. The only exception was a significant overrepresentation of cases with positive locoregional lymph nodes in the radiation-associated pediatric/adolescent PTC group homozygous for 72Argencoding allele $(\mathrm{P}=0.02)$. In heterozygous Arg/Pro individuals from the same group there was a tendency to lower incidence of lymph node involvement compared to patients with other TP53 genotypes. On the contrary, in the radiation-associated adult PTCs, TP53 heterozygosity strongly tended to associate with increased rate of metastases to local lymph nodes. However, for both of these, the trends was statistically insignificant ( $\mathrm{P}=0.08$ and $\mathrm{P}>0.05$, respectively). In the sporadic PTC group, no genotype-phenotype associations were observed.

Altogether, the data demonstrate that none of TP53 genotypes is likely to be specifically linked to histological tumor variants in PTC. Some particular associations may occur within certain age groups with regard to the local lymph node status but these are not necessarily paralleled in other PTC groups of different age or etiology.

\section{Discussion}

In this study, we have analyzed TP53 72Arg- or 72Proencoding allele distribution in two radiation-associated groups of PTCs and sporadic cases. A significantly decreased number of Arg/Arg patients in the adult radiation-associated PTC group was revealed compared to the sporadic PTCs and control population. In pediatric/adolescent PTCs, homozygous Arg genotype deficiency was not observed ruling out the possibility of its association with younger age of the radiation-exposed adult patients compared to the sporadic PTC group. This finding is further strengthened by the lack of TP53 genotype association with individuals' age and gender in the control population. Latency was found to be nearly even in the radiation-associated childhood/adolescent and adult PTC cases, therefore older age of patients in the adult group was due to the older age at presumed exposure but not to the longer period of time between exposure and disease onset. Hence, underrepresentation of homozygous Arg is specific to adult post-Chernobyl patients which may suggest an age related difference in the thyroid's biological reaction to radiation exposure. It is tempting to speculate that such a difference may in part be dependent on the propensity of the 72Pro p53 isoform to induce cell death less efficiently, but age-associated particularities of this biological framework remain to be clarified.

Next, we addressed a question whether TP53 loss of heterozygosity, a mechanism of tumor suppressor gene inactivation in various types of human cancers, might have taken place in the studied PTCs. Our results are in agreement with previous reports of infrequent allelic loss and/or TP53 gene mutation in PTC which are more common in undifferentiated thyroid cancer $(29,35,36)$. In addition, we determined that expression levels of Arg- and Pro-encoding alleles in heterozygous cases were essentially even in both PTC tissue and normal thyroid counterpart suggesting no cancer-associated bias or imprinting. It has been shown that imbalanced allele expression of a tumor suppressor gene may be linked to cancer risk (37). Our data demonstrate this has not been the case for radiationassociated or sporadic PTCs, at least with respect to TP53. In approximately $10 \%$ of patients biased allele expression was detected, but interestingly, this was present in both the tumor and normal thyroid tissues from the same individual. Therefore, it was not a result of cell transformation, but rather a systemic (epi)genetic modification whose nature in each particular case may be different and comprise a matter of a separate investigation.

We also attempted to verify TP53 genotype association with PTC morphology. Histological features of postChernobyl PTCs have been shown to markedly differ from those of sporadic adult PTCs $(38,39)$, a circumstance that may potentially be misleading if genotype-morphology comparison was performed between PTC groups of different ages at operation. When analysis was done within each separate PTC group, no significant association was revealed between particular TP53 genotype and major histological component of the tumor. There has been no data in the literature on TP53 polymorphism association with thyroid cancer morphology to compare, but results obtained for other types of human malignancies, such as ovarian (40) and gastric cancer (41), suggest such correlation may not be commonly linked to a germline polymorphism.

No association has been previously found between PTC aggressiveness and p53 polymorphism (15). Our results support this in respect of sporadic PTC cases. However, in the post-Chernobyl cases, a significant correlation with lymph node involvement occurred in radiation-associated pediatric/ adolescent subgroup homozygous for Arg allele whereas the Arg/Pro genotype displayed a tendency to an inverse association. In radiation-associated adult PTCs, we were unable to demonstrate the same correlation. This, apparently agedependent difference, may be explained, at least in part, by the differing TP53 genotype prevalence in radiation-associated pediatric/adolescent and adult subgroups. Homozygous Arg and heterozygous Arg/Pro accounted for about $90 \%$ of cases in these subgroups; lymph node involvement was present in 
half of the adult radiation-associated cases and in slightly greater proportion of pediatric/adolescent PTCs. Since relative numerical superiority of homozygous Arg cases in the younger subgroup is higher than in adults, it becomes possible to trace the mentioned finding. It is also possible that the association between TP53 genotype and lymph node involvement may interact with the age related molecular biological profile of PTC. Rearrangements, such as ret/PTC $(42,43)$ or the recently discovered AKAP9-BRAF fusion (44) are more common in PTC patients diagnosed at a younger age, whereas $B R A F^{T 1799 A}$ transversion occurs mostly in adult PTCs (45-47). At present, nothing has been reported on the cross-talk between thyroidspecific activated oncogenic proteins and p53 isoforms, or on the impact of such cooperation on the biological behavior of a tumor.

Our data are at some variance with Granja et al findings who have shown a significant overrepresentation of homozygous Pro genotype in Brazilian PTC patients with respect to a control population (15). The main factor accounting for such a discrepancy may be a difference in the genetic background of individuals enrolled in the reported and present studies: our estimates show a significant difference between the genotype distribution in Brazilian and Russian-Ukrainian population $\left(\mathrm{P}<0.0001, \chi^{2}\right.$ test $)$, resulting in a lower proportion of homozygous Pro individuals in the former. On the other hand, allelic frequencies in our control group were similar to those previously reported in healthy individuals from USA (Caucasian women) (48), England (19), Germany (20) and Czech (21). In a study of German patients with thyroid cancer, Boltze et al found PTC to be devoid of homozygous Pro genotype (14), but this was challenged by the Brazilian laboratory (15). In our series, we also detected Pro/Pro in PTCs at nearly the same frequency as it was in the group(s) of comparison, perhaps due to greater number of cases examined by us than in the cited work $(n=21)$. Thus, our results indicate that homozygous Pro genotype may occur in Caucasians with PTC, and that TP53 allelic prevalence may vary in PTC patients with differing genetic backgrounds.

In summary, our data show, for the first time, a significant decrease of homozygous Arg TP53 genotype prevalence in adult patients with radiation-associated PTC as compared to sporadic PTC cases and general population suggestive that other TP53 allele combinations may contribute to a risk of papillary thyroid cancer in individuals exposed during their late childhood, adolescence or in young adult age (for females). In the tumors, cell transformation does not lead to allelic loss or biased TP53 allele expression in heterozygous individuals. None of TP53 genotypes specifically associates with tumor morphology, however, some particular correlations with manifestations of tumor aggressiveness may occur in certain age groups of radiation-associated but not in adult sporadic PTCs. We assume these data together with elucidation of other individual genetic characteristics, which is an intriguing future experimental task, may be of importance for identification of groups at risk for radiationassociated thyroid cancer both retrospectively and prospectively if exposure is anticipated. Also, our results indicate that TP53 polymorphic status needs to be taken into account for correct planning and interpretation of studies on radiation health effects on the human thyroid.

\section{Acknowledgements}

This study was supported in part by Research Grant 16510037 to K.A., Research Grant 15590981 to H.N., Research Grant 15390295 to S.Y. (all grants from Ministry of Education, Culture, Sports, Science and Technology of Japan), and Nagasaki University 21st Century COE Program.

\section{References}

1. Slee EA, O'Connor DJ and Lu X: To die or not to die: how does p53 decide? Oncogene 23: 2809-2818, 2004.

2. Vogelstein B, Lane D and Lvine AJ: Surfing the p53 network. Nature 408: 307-310, 2000.

3. Vousden KH and Lu X: Live or let die: the cell's response to p53. Nat Rev Cancer 2: 594-604, 2002.

4. Sansome C, Zaika A, Marchenko ND and Moll UM: Hypoxia death stimulus induces translocation of $\mathrm{p} 53$ protein to mitochondria. Detection by immunofluorescence on whole cells. FEBS Lett 488: 110-115, 2001

5. Marchenko ND, Zaika A and Moll UM: Death signal-induced localization of p53 protein to mitochondria. A potential role in apoptotic signaling. J Biol Chem 275: 16202-16212, 2000.

6. Dumont P, Leu JI, Della Pietra AC III, George DL and Murphy M: The codon 72 polymorphic variants of p53 have markedly different apoptotic potential. Nat Genet 33: 357-365, 2003.

7. Zilfou JT, Hoffman WH, Sank M, George DL and Murphy M: The corepressor $\mathrm{mSin} 3 \mathrm{a}$ interacts with the proline-rich domain of p53 and protects p53 from proteasome-mediated degradation. Mol Cell Biol 21: 3974-3985, 2001.

8. Buyru N, Tigli H and Dalay N: P53 codon 72 polymorphism in breast cancer. Oncol Rep 10: 711-714, 2003.

9. Langerod A, Bukholm IR, Bregard A, Lonning PE, Andersen TI, Rognum TO, Meling GI, Lothe RA and Borresen-Dale AL: The TP53 codon 72 polymorphism may affect the function of TP53 mutations in breast carcinomas but not in colorectal carcinomas. Cancer Epidemiol Biomarkers Prev 11: 1684-1688, 2002.

10. Storey A, Thomas M, Kalita A, Harwood C, Gardiol D, Mantovani F, Breuer J, Leigh IM, Matlashewski G and Banks L: Role of a p53 polymorphism in the development of human papillomavirus-associated cancer. Nature 393: 229-234, 1998.

11. Arbel-Alon S, Menczer J, Feldman N, Glezerman M, Yeremin L and Friedman E: Codon 72 polymorphism of p53 in Israel jewish cervical cancer patients and healthy women. Int J Gynecol Cancer 12: 741-744, 2002.

12. Papadakis ED, Soulitzis N and Spandidos DA: Assocation of p53 codon 72 polymorphism with advanced lung cancer: the Arg allele is preferentially retained in tumours arising in Arg/Pro germline heterozygotes. Br J Cancer 87: 1013-1018, 2002.

13. Cairey-Remonnay S, Humbey O, Mougin C, Algros MP, Mauny F, Kanitakis J, Euvrard S, Laurent R and Aubin F: TP53 polymorphism of exon 4 at codon 72 in cutaneous squamous cell carcinoma and benign epithelial lesions of renal transplant recipients and immunocompetent individuals: lack of correlation with human papillomavirus status. J Invest Dermatology 118: 1026-1031, 2002.

14. Boltze C, Roessner A, Landt O, Szibor R, Peters B and Schneider-Stock R: Homozygous proline at codon 72 of p53 as a potential risk factor favoring the development of undifferentiated thyroid carcinoma. Int J Oncol 21: 1151-1154, 2002.

15. Granja F, Morari J, Morari EC, Correa LAC, Assumpcao LVM and Ward LS: Proline homozygosity in codon 72 of p53 is a factor of susceptibility for thyroid cancer. Cancer Lett 210: 151-157, 2004.

16. Anzola M, Cuevas N, Lopez-Martinez M, Saiz A, Burgos JJ and De Pancorbo MM: Frequent loss of p53 codon 72 Pro variant in hepatitis $C$ virus-positive carriers with hepatocellular carcinoma. Cancer Lett 193: 199-205, 2003.

17. Hogdall EV, Hogdall CK, Christensen L, Glud E, Blaakaer J, Bock JE, Vuust J, Norgaard-Pedersen B and Kjaer SK: Distribution of p53 codon 72 polymorphisms in ovarian tumour patients and their prognostic significance in ovarian cancer patients. Anticancer Res 22: 1859-1864, 2002.

18. Biros E, Kalina I, Kohut A, Bogyiova E, Salagovic J and Sulla I: Allelic and haplotype frequencies of the p53 polymorphisms in brain tumor patients. Physiol Res 51: 59-64, 2002. 
19. Rosenthal AN, Ryan A, Al-Jehani RM, Storey A, Harwood CA and Jacobs IJ: p53 codon 72 polymorphism and risk of cervical cancer in UK. Lancet 352: 871-872, 1998.

20. Klaes R, Ridder R, Schaefer U, Benner A and von Knebel Doeberitz M: No evidence of p53 allele-specific predisposition in human papillomavirus-associated cervical cancer. J Mol Med 77: 299-302, 1999.

21. Tachezy R, Mikyskova I, Salakova M and van Ranst M: Correlation between human papillomavirus-associated cervical cancer and p53 codon 72 arginine/proline polymorphism. Hum Genet 105: 564-566, 1999.

22. Hamajima N, Matsuo K, Suzuki T, Nakamura T, Matsuura A, Hatooka S, Shinoda M, Kodera Y, Yamamura Y and Tajima K: No associations of p73 G4C14-to-A4T14 at exon 2 and p53 Arg72Pro polymorphisms with the risk of digestive tract cancers in Japanese. Cancer Lett 181: 81-85, 2002.

23. Rubino C, Cailleux AF, De Vathaire F and Schlumberger M: Thyroid cancer after radiation exposure. Eur J Cancer 38: 645-647, 2002.

24. Mettler FH Jr, Becker DV, Wachholz BW and Bouville AC: Chernobyl: 10 years later. J Nucl Med 37: 24N, 26N-27N, 1996.

25. Jacob P, Kenigsberg Y, Zvonova I, Goulko G, Buglova E, Heidenreich WF, Golovneva A, Bratilova AA, Drozdovitch V and Paretzke HG: Childhood exposure due to the Chernobyl accident and thyroid cancer risk in contaminated areas of Belarus and Russia. Br J Cancer 80: 1461-1469, 1999.

26. Hillebrandt S, Streffer C, Reiners $C$ and Demidchik E: Mutations in p53 tumor suppressor gene in thyroid carcinomas of children from areas contaminated by the Chernobyl accident. Int J Radiat Biol 69: 39-45, 1996.

27. Nikiforov YE, Nikiforova MN, Gnepp DR and Fagin JA: Prevalence of mutations of ras and p53 in benign and malignant thyroid tumors from children exposed to radiation after the Chernobyl nuclear accident. Oncogene 13: 687-693, 1996.

28. Suchy B, Waldmann V, Klugbauer S and Rabes HM: Absence of RAS and p53 mutations in thyroid carcinomas of children after Chernobyl in contrast to adult thyroid tumours. Br J Cancer 77: 952-955, 1998.

29. Salvatore D, Celetti A, Fabien N, Paulin C, Martelli ML, Battaglia C, Califano D, Monaco C, Viglietto G and Fusco A: Low frequency of p53 mutations in human thyroid tumours; $p 53$ and Ras mutation in two out of fifty-six thyroid tumours. Eur J Endocrinol 134: 177-183, 1996.

30. Yang T, Namba H, Hara T, Takamura N, Nagayama Y, Fukata S, Ishikawa N, Kuma K, Ito K and Yamashita S: p53 induced by ionizing radiation mediates DNA end-jointing activity, but not apoptosis in thyroid cells. Oncogene 14: 1511-1519, 1997.

31. Ivanov VK, Gorski AI, Maksioutov MA, Vlasov OK, Godko AM, Tsyb AF, Tirmarche M, Valenty M and Verger P: Thyroid cancer incidence among adolescents and adults in the Bryansk region of Russia following the Chernobyl accident. Health Physics 84: 46-60, 2003.

32. Hedinger C, Williams ED and Sobin LH: Histological typing of thyroid tumors. In: WHO International Histological Classification of Tumors. 2nd edition. Hedinger C, Williams ED and Sobin LH (eds). Springer-Verlag, Berlin, 1988.

33. De Groot LJ, Kaplan EL, McCormick M and Straus FH: Natural history, treatment and course of papillary thyroid carcinoma. J Clin Endocrinol Metab 71: 414-424, 1990.

34. SAS/STAT User's Guide, Version 8. Cary, NC: SAS Insitute Inc., p3884, 1999.
35. Fagin JA, Matsuo K, Karmakar A, Chen DL, Tang SH and Koeffler HP: High prevalence of mutations of the p53 gene in poorly differentiated human thyroid carcinomas. J Clin Invest 91: 179-184, 1993.

36. Ito T, Seyama T, Mizuno T, Tsuyama N, Hayashi T, Hayashi $\mathrm{Y}$, Dohi $\mathrm{K}$, Nakamura $\mathrm{N}$ and Akiyama $\mathrm{M}$ : Unique association of p53 mutations with undifferentiated but not with differentiated carcinomas of the thyroid gland. Cancer Res 52: 1369-1371, 1992.

37. Yan H, Dobbie Z, Gruber SB, Markowitz S, Romans K, Giardiello FM, Kinzler KW and Vogelstein B: Small changes in expression affect predisposition to tumorigenesis. Nat Genet 30: 25-26, 2002

38. Nikiforov YE and Gnepp DR: Pathomorphology of thyroid gland lesions associated with radiation exposure: the Chernobyl experience and review of the literature. Adv Anat Pathol 6: 78-91, 1999.

39. Williams D: Cancer after nuclear fallout: lessons from the Chernobyl accident. Nat Rev Cancer 2: 543-549, 2002.

40. Wang Y, Kringen P, Kristensen GB, Holm R, Baekelandt MM, Olivier M, Skomedal H, Hainaut P, Trope CG and Helland A: Effect of the codon 72 polymorphism (c.215G $>$ C, p.Arg72Pro) in combination with somatic sequence variants in the TP53 gene on survival in patients with advanced ovarian carcinoma. Hum Mutat 24: 21-34, 2004

41. Zhang ZW, Laurence NJ, Hollowood A, Newcomb P, Moorghen M, Gupta J, Feakins R, Farthing MJ, Alderson D and Holly J: Prognostic value of TP53 codon 72 polymorphism in advanced gastric adenocarcinoma. Clin Cancer Res 10: 131-135, 2004.

42. Tuttle RM and Becker DV: The Chernobyl accident and its consequences: update at the millennium. Semin Nucl Med 30: 133-140, 2000.

43. Nikiforov YE: RET/PTC rearrangement in thyroid tumors. Endocr Pathol 13: 3-16, 2002.

44. Ciampi R, Knauf JA, Kerler R, Gandhi M, Zhu Z, Nikiforova MN, Rabes HM, Fagin JA and Nikiforov YE: Oncogenic AKAP9BRAF fusion is a novel mechanism of MAPK pathway activation in thyroid cancer. J Clin Invest 115: 94-101, 2005.

45. Nikiforova MN, Ciampi R, Salvatore G, Santoro M, Gandhi M, Knauf JA, Thomas GA, Jeremiah S, Bogdanova TI and Nikiforov YE: Low prevalence of BRAF mutations in radiationinduced thyroid tumors in contrast to sporadic papillary carcinomas. Cancer Lett 209: 1-6, 2004.

46. Lima J, Trovisco V, Soares P, Maximo V, Magalhaes J, Salvatore G, Santoro M, Bogdanova T, Tronko M and SobrinhoSimoes M: BRAF mutations are not a major event in postChernobyl childhood thyroid carcinomas. J Clin Endocrinol Metab 89: 4267-4271, 2004.

47. Kumagai A, Namba H, Saenko VA, Ashizawa K, Ohtsuru A, Ito M, Ishikawa N, Sugino K, Ito K and Yamashita S: Low frequency of BRAFT1796A mutations in childhood thyroid carcinomas. J Clin Endocrinol Metab 89: 4280-4284, 2004.

48. Madeleine MM, Shera K, Schwartz SM, Daling JR, Galloway DA, Wipf GC, Carter JJ, McKnight B and McDougall JK: The p53 Arg72Pro polymorphism, human papillomavirus and invasive squamous cell cervical cancer. Cancer Epidemiol Biomarkers Prev 9: 225-227, 2000. 